\title{
Osteopontin expression in the invasive front stroma of colorectal adenocarcinoma is associated with tumor budding and prognosis
}

Takeshi Uehara ( $\nabla$ tuehara@shinshu-u.ac.jp )

Shinshu University

Tomoyuki Nakajima

Shinshu University

Mai Iwaya

Shinshu University

Kazuyuki Matsuda

Shinshu University

Megumi Wada

Nagano Red Cross Hospital

Tadanobu Nagaya

Shinshu University

Yusuke Miyagawa

Shinshu University

Hiroyoshi Ohta

Shinshu University

\section{Research Article}

Keywords: tumor budding, colorectal carcinoma, osteopontin, CD44v6

Posted Date: March 2nd, 2022

DOI: https://doi.org/10.21203/rs.3.rs-1319216/v1

License: (c) (1) This work is licensed under a Creative Commons Attribution 4.0 International License.

Read Full License 


\section{Abstract}

Background: Tumor budding (TB) is an important prognostic factor in colorectal carcinoma (CRC). Osteopontin (OPN) functions in various processes such as immune response, migration and invasion, angiogenesis, epithelial-mesenchymal transition (EMT) and metastasis. However, the involvement of OPN and CD44v6, which is a receptor for OPN, in TB has not been clarified. Therefore, we examined the relationship of OPN with TB in CRC and compared the clinicopathological features.

Methods: We investigated the expression of OPN and CD44v6 in 83 cases of CRC by immunostaining and analyzed the clinicopathological features.

Results: OPN expression was observed only in the cytoplasm of stromal cells such as macrophages and fibroblasts, and not cancer cells. There was a significant correlation between OPN positivity and the degree of differentiation at the invasive front and TB grade. CD44v6 was positive in cancer cells in 72 cases $(86.7 \%)$ and negative in 11 cases (13.3\%). A statistically significant effect on overall survival (OS) was identified between the OPN-positive group [median OS: 1586 (range, 30-2749) days] and the OPNnegative group [median OS: 1901 (range, 8-2665) days] (log-rank test, $p=0.011$ ).

Conclusions: OPN analysis may reveal factors that influence prognosis.

\section{Background}

Colorectal adenocarcinoma (CRC) is one of the most common carcinomas worldwide [1] and is graded as well, moderately, and poorly differentiated (solid type and non-solid type) according to the gland structure. Notably, the poorly differentiated type has a poor prognosis, and the non-solid type has a worse prognosis compared with the solid type[2]. Histopathological factors for the prognostication of patients with CRC include disease stage, lymphovascular invasion, lymph node metastasis, and tumor budding (TB) $[3,4]$. TB is defined as an individual tumor cell or a cluster of four tumor cells or fewer at the invasive front $[3,5]$, and is an independent poor prognostic factor in CRC [3,6-10]. Although TB was considered to be a morphological characteristic mirroring EMT, most evidence in recent years has suggested that it consists of partial EMT cancer cells showing a hybrid epithelial/mesenchymal (E/M) phenotype that does not exhibit a complete mesenchymal phenotype[11-13].

In cancer tissues, not only cancer cells but also the surrounding stromal cells are components of the tumor microenvironment. The tumor microenvironment, which is composed of a wide variety of cells, is deeply involved in the proliferation, invasion, and metastasis of cancer cells through the interactions between cells via cytokines and growth factors. Among them, tumor-associated macrophages (TAMs) promote tumor growth, invasion, metastasis, and angiogenesis by producing VEGF, PDGF, TGF- $\beta$, and matrix metalloproteinase (MMP)[14].

Osteopontin (OPN) was identified as a secretory glycosylated phosphoprotein secreted from bone, and was subsequently reported to be secreted from various cells such as macrophages[15-17], 
fibroblasts[18], and cancer cells [19]. OPN in the tumor microenvironment functions in various processes such as the immune response, migration and invasion, angiogenesis, EMT, and metastasis[20, 21]. OPN has an arginine-glycine-aspartic acid (RGD) motif and interacts with integrin and CD44 as major receptors. CD44 produces a polymorphic group of proteins (85-250 kDa in size) by alternative splicing via epithelial splicing regulatory proteins (ESRPs)[22]. The standard CD44 isoform is composed of only constitutive exons, and the variant CD44v isoform contains one or more variable exons. Among them, CD44v6 and CD44v7 are important structures for cancer invasion and metastasis promoted by OPN[23].

There are few reports on the relationship between OPN and TB. Therefore, we performed a clinicopathological analysis of OPN expression and TB.

\section{Methods}

\section{Surgical specimens}

In this retrospective clinicopathological analysis, we reviewed 83 cases of CRC TNM stage II-IV that underwent resection at Shinshu University Hospital, Matsumoto, Japan, between 2012 and 2015. We selected the block with deepest depth of tumor invasion in each case. This study was approved by the Committee for Medical Ethics of Shinshu University School of Medicine (no. 4088).

\section{Evaluation of tumor budding}

For each analysis, Hematoxylin and Eosin (H\&E) staining slides were independently evaluated by two experienced pathologists (T.U. and M.I.) who were blinded to the clinical data. Tumor budding was defined as the findings of individual cells or small clusters (maximum of five cells) at the tumor invasion front. TB was graded as Bd1 (0-4 buds), Bd2 (5-9 buds), and Bd3 ( $\geq 10$ buds), as described in a previous report [8]. Furthermore, TB was graded as low (Bd1) or high (Bd2 and Bd3).

\section{Immunohistochemistry}

Specimens obtained by surgery were fixed in $20 \%$ neutral buffered formalin. After fixing, they were then dehydrated in alcohols, and embedded in paraffin. Serial sections of $3 \mu \mathrm{m}$-thickness were cut for immunohistochemical staining, in addition to H\&E staining. The stained sections were deparaffinized and soaked $0.3 \% \mathrm{H}_{2} \mathrm{O}_{2}$ diluted with methanol for $30 \mathrm{~min}$ at room temperature with gentle agitation to block endogenous peroxidase. Antigen retrieval was performed as follows: for OPN (22952-1-AP , 1:200; Proteintech, Chicago, IL, USA) and cytokeratin AE1/AE3 (AE1/AE3 1:100; Leica Biosystems, Newcastle, UK) sections were boiled in $0.45 \%$ Tris-5mM EDTA solution using a microwave at $600 \mathrm{~W}$ for $25 \mathrm{~min}$; for CD44v6 (ab78960, 1:500; Abcam, Cambridge, UK), sections were boiled in Histofine antigen retrieval solution ( $\mathrm{pH}$ 9.0; Nichirei Biosciences, Tokyo, Japan) using a Pascal pressurized heating chamber (Dako, Carpinteria, CA, USA) at $115^{\circ} \mathrm{C}$ for $10 \mathrm{~min}$. Sections were incubated with each OPN (1:200), cytokeratin 
AE1/AE3 (1:100), and CD44v6 (1:500) antibody for $1 \mathrm{~h}$ at room temperature. Immunohistochemistry was performed using the EnVision method and visualized using diaminobenzidine. All stained sections were counterstained with hematoxylin.

OPN positivity was measured at the three sites that showed the strongest immunoreactivity in each case, and the average value was calculated.

\section{Statistical analysis}

Pearson's chi-squared test, log-rank test, and Cox proportional hazard regression analysis were performed using JMP Statistics software version 13 (JMP, Tokyo, Japan). A p-value of less than 0.05 was considered significant.

\section{Results}

In areas of normal colonic mucosa, OPN immunoreactivity was almost non-existent in epithelial, stromal, and inflammatory cells. In cancer tissue, OPN immunoreactivity was observed only in the cytoplasm of stromal cells such as macrophages and fibroblasts, but not cancer cells (Fig. 1). OPN-positive cells were also found in cancer stroma, but were mostly localized at the invasive front. OPN positivity in the stromal cells of the invasive front was measured at the three sites that showed the strongest immunoreactivity in each case, and OPN positivity was measured as $0-86.8 \%$ (median, $14.7 \%$ ). All cases used in the analysis were evaluated for TB; the results are shown in Table 1. The evaluation of other clinicopathological factors is also shown in Table 1. There was a significant correlation between OPN positivity in stromal cells at the invasive front and the degree of differentiation at the invasive front and TB grade. Because secreted OPN binds to CD44, especially CD44v6[23], we performed immunohistochemical staining of CD44v6 (Fig. 2). CD44v6 (Fig. 2) was positive in 72 cases (86.7\%) and negative in 11 cases (13.3\%). 
Table 1

Correlation between clinicopathological factors and OPN expression

\begin{tabular}{|c|c|c|c|c|}
\hline & & OPN & & \\
\hline & $\mathrm{n}$ & Low & High & $p$-value \\
\hline Sex & & & & \\
\hline Male & 48 & 24 & 24 & 0.898 \\
\hline Female & 35 & 18 & 17 & \\
\hline Age, years & & & & \\
\hline$<69$ & 43 & 24 & 19 & 0.328 \\
\hline$\geq 69$ & 40 & 18 & 22 & \\
\hline Depth of tumor it & & & & \\
\hline SM, MP & 14 & 8 & 6 & 0.594 \\
\hline SS & 69 & 34 & 35 & \\
\hline Lymphovascular & & & & \\
\hline Absent & 7 & 4 & 3 & 0.719 \\
\hline Present & 76 & 38 & 38 & \\
\hline Lymph node met & & & & \\
\hline Absent & 42 & 21 & 21 & 0.912 \\
\hline Present & 41 & 21 & 20 & \\
\hline Pathological sta & & & & \\
\hline II & 35 & 18 & 17 & 0.898 \\
\hline III, IV & 48 & 24 & 24 & \\
\hline Degree of differe & & & & \\
\hline tub1, tub2, por1 & 49 & 34 & 15 & $<0.001^{*}$ \\
\hline por2 & 34 & 8 & 26 & \\
\hline Tumor budding & & & & \\
\hline Grade 1 & 50 & 35 & 15 & $<0.001^{*}$ \\
\hline Grade 2, 3 & 33 & 7 & 26 & \\
\hline
\end{tabular}




\section{OPN}

*Statistically significant

SM: submucosa; MP: muscularis propria; SS: subserosa; tub1: well-differentiated tubular adenocarcinoma; tub2: moderately differentiated tubular adenocarcinoma; por1: solid type poorly differentiated adenocarcinoma; por2: non-solid type poorly differentiated adenocarcinoma

The prognostic value of the OPN-positive and OPN-negative groups was assessed by Kaplan-Meier analysis and the log-rank test. A statistically significant effect was found in OS between the OPN-positive group [median OS: 1586 (range, 30-2749) days] and the OPN-negative group [median OS: 1901 (range, 8-2665) days] (log-rank test, $p=0.011$ ) (Fig. 3).

\section{Discussion}

The findings of our study indicated that the relationship between OPN expression and TB in invasive-front stromal cells may be related to the EMT-promoting effect of OPN. In TB, the cell-cell adhesion of cancer cells is attenuated, and cancer cell motility and invasiveness are enhanced[24]. Binding of OPN to cancer cells expressing CD44v6 promotes EMT[25]. Our study demonstrated CD44v6 expression in $86.7 \%$ of cases, suggesting that OPN produced by stromal cells may promote the acquisition of EMT via CD44v6. In many sporadic colorectal cancers, APC inactivation occurs during the carcinogenesis process and $\beta$ catenin translocation into the nucleus is increased[26]. $\beta$-catenin associates with transcription factors and induces the transcription of target genes. The upregulation of CD44v6 in CRC is due to the fact that CD44 belongs to the target gene group of the Wnt/ $\beta$-catenin signaling pathway[27]. CD44 has a standard type (CD44s) and a variant type (CD44v) derived from alternative splicing. Among them, the C-terminal fragment of OPN strongly binds to CD44v6 $[28,29]$. It has been reported that the binding of CD44 and OPN induces the expression of Twist, which promotes the transcription of EMT-related genes by activating the PI3K/AKT signaling pathway[30, 31]. EMT reduces the binding between adjacent cells because of strong epithelial binding, and enhances motility, invasion, and metastasis by acquiring mesenchymal cell-like characteristics[32]. Observation of OPN expression in the TB region may be an important factor for prognosis in CRC.

It has also been reported that the binding of OPN to CD44 promotes the production of MMP-2 and MMP9. MMP-2 is involved in cancer cell invasion by degrading the extracellular matrix, and MMP-9 activates TGF- $\beta[33$ ]. Binding of TGF- $\beta$ to the TGF- $\beta$ receptor induces phosphorylation of SMAD2/3 and promotes transcription of EMT-related genes by SMAD4[33]. Recent studies have revealed that partial EMT, called the hybrid E/M phenotype, has been observed in cancer cells at the invasive front and plays an important role in the invasion of cancer cells[34-36]. OPN expression in stromal cells of the invasive front, as observed in this study, may contribute to the acquisition of the hybrid E/M phenotype by CD44-mediated interactions. It contributes to OPN-mediated interactions between stromal cells and cancer cells and 
induces the production of EMT-promoting proteins and the degradation of the extracellular matrix, resulting in decreased cell-cell adhesion of cancer cells and enhanced motility and invasion. These mechanisms may have led to the poorly differentiated histology and high-grade TB in this study.

OPN not only promotes migration and invasion in TB, but also has cancer stem cell properties[37]. We have not been able to demonstrate TB and stem cell features in previous studies[38], but there are reports suggesting some associations[37, 39]. In addition, cancer stem cells in CRC expressing CD44v6 promote metastasis[25]. Suppression of OPN may lead to the downregulation of cancer stem cells themselves and as well as infiltration and metastasis.

Our study has some limitations. Our analysis was performed in a limited number of cases. It is also necessary to investigate the possibility that suppression of OPN expression causes TB in cultured cells.

\section{Conclusions}

In conclusion, OPN analysis may reveal factors that influence prognosis.

\section{Abbreviations}

TB, tumor budding; CRC, colorectal carcinoma; EMT, epithelial-mesenchymal transition; OPN, osteopontin; TAM, tumor-associated macrophage; MMP, matrix metalloproteinase.

\section{Declarations}

\section{Ethics approval and consent to participate}

The study protocol conformed to the Declaration of Helsinki and was approved by the research ethics committee of the Shinshu University School of Medicine (approval code: 4088). The need for informed consent was waived by the ethics committee by giving the participants the opportunity to opt out on the website of Shinshu University School of Medicine.

\section{Consent for publication}

Not applicable.

\section{Availability of data and materials}

All data generated and analyzed during the current study are available from the corresponding author on reasonable request. Data will not be disclosed due to privacy or ethical restrictions. 


\section{Competing interests}

The authors declare that they have no competing interests.

\section{Funding}

This work was supported by Japan Society for the Promotion of Science KAKENHI Grant-in-Aid for Young Scientists (grant number JP21384207).

\section{Authors' contributions}

TN participated in the design of the study, performed the pathological analysis, and drafted the manuscript. TU and MI helped with the pathological analysis. TU performed the statistical analysis. MW and $\mathrm{KM}$ conducted the immunohistochemistry. TN and YM examined the clinical data of cases. $\mathrm{HO}$ critically revised the draft for important intellectual content. All authors have read and approved the manuscript.

\section{Acknowledgments}

We are grateful to Yukihoro Kobayashi, Masanobu Momose, Yasuyo Shimojo, Naoko Ogiwara, Akiko Inamura, Chitoshi Arai, Marina Nuno, Kanade Wakabayashi, Yasuhiro Kinugawa, and Naoko Yamaoka at Shinshu University Hospital for their excellent technical assistance. We also thank H. Nikki March, PhD, from Edanz (https://jp.edanz.com/ac) for editing a draft of this manuscript.

\section{References}

1. Navarro M, Nicolas A, Ferrandez A, Lanas A: Colorectal cancer population screening programs worldwide in 2016: An update. (2219-2840 (Electronic)).

2. Goi T, Hirono Y Fau - Katayama K, Katayama K Fau - Yamaguchi A, Yamaguchi A: Microsatellite instability and survival rate in the solid or nonsolid types of poorly differentiated colorectal adenocarcinoma. (0020-8868 (Print)).

3. Hase K, Shatney C, Johnson D, Trollope M, Vierra M: Prognostic value of tumor"budding"in patients with colorectal cancer. Diseases of the Colon \& Rectum1993, 36(7):627-635.

4. Akagi Y, Adachi Y Fau - Ohchi T, Ohchi T Fau - Kinugasa T, Kinugasa T Fau - Shirouzu K, Shirouzu K: Prognostic impact of lymphatic invasion of colorectal cancer: a single-center analysis of 1,616 patients over 24 years. (1791-7530 (Electronic)).

5. Lugli A, Kirsch R, Ajioka Y, Bosman F, Cathomas G, Dawson H, El Zimaity H, Fléjou J-F, Hansen TP, Hartmann Aet al: Recommendations for reporting tumor budding in colorectal cancer based on the 
International Tumor Budding Consensus Conference (ITBCC) 2016. Modern Pathology2017, 30(9):1299-1311.

6. Mitrovic B, Schaeffer DF, Riddell RH, Kirsch R: Tumor budding in colorectal carcinoma: time to take notice. Modern Pathology2012, 25(10):1315-1325.

7. van Wyk HC, Park J, Roxburgh C, Horgan P, Foulis A, McMillan DC: The role of tumour budding in predicting survival in patients with primary operable colorectal cancer: A systematic review. Cancer Treatment Reviews2015, 41(2):151-159.

8. De Smedt L, Palmans S, Sagaert X: Tumour budding in colorectal cancer: what do we know and what can we do? Virchows Archiv2016, 468(4):397-408.

9. Rogers AC, Winter DC, Heeney A, Gibbons D, Lugli A, Puppa G, Sheahan K: Systematic review and meta-analysis of the impact of tumour budding in colorectal cancer. British Journal of Cancer2016, 115(7):831-840.

10. Ueno H, Mochizuki H, Hashiguchi Y, Shimazaki H, Aida S, Hase K, Matsukuma S, Kanai T, Kurihara H, Ozawa Ket al: Risk factors for an adverse outcome in early invasive colorectal carcinoma. Gastroenterology2004, 127(2):385-394.

11. Grigore AD, Jolly MK, Jia D, Farach-Carson MC, Levine H: Tumor Budding: The Name is EMT. Partial EMT. Journal of Clinical Medicine2016, 5(5).

12. Kohler I, Bronsert P, Timme S, Werner M, Brabletz T, Hopt UT, Schilling O, Bausch D, Keck T, Wellner UF: Detailed analysis of epithelial-mesenchymal transition and tumor budding identifies predictors of long-term survival in pancreatic ductal adenocarcinoma. Journal of Gastroenterology and Hepatology2015, 30(S1):78-84.

13. Bronsert P, Enderle-Ammour K, Bader M, Timme S, Kuehs M, Csanadi A, Kayser G, Kohler I, Bausch D, Hoeppner Jet al: Cancer cell invasion and EMT marker expression: a three-dimensional study of the human cancer-host interface. The Journal of Pathology2014, 234(3):410-422.

14. Solinas G, Germano G, Mantovani A, Allavena P: Tumor-associated macrophages (TAM) as major players of the cancer-related inflammation. Journal of Leukocyte Biology2009, 86(5):1065-1073.

15. Murry CE, Giachelli CM, Schwartz SM, Vracko R: Macrophages express osteopontin during repair of myocardial necrosis. Am J Patho/1994, 145(6):1450-1462.

16. Giachelli CM, Lombardi D, Johnson RJ, Murry CE, Almeida M: Evidence for a role of osteopontin in macrophage infiltration in response to pathological stimuli in vivo. Am J Patho/1998, 152(2):353358.

17. Rittling SR: Osteopontin in macrophage function. Expert Reviews in Molecular Medicine2011, 13:e15.

18. Ashizawa N, Graf K, Do YS, Nunohiro T, Giachelli CM, Meehan WP, Tuan TL, Hsueh WA: Osteopontin is produced by rat cardiac fibroblasts and mediates $A(I I)$-induced DNA synthesis and collagen gel contraction. The Journal of Clinical Investigation1996, 98(10):2218-2227.

19. Sodek J, Ganss B, McKee MD: Osteopontin. Critical Reviews in Oral Biology \& Medicine2000, 11(3):279-303. 
20. Zhao H, Chen Q, Alam A, Cui J, Suen KC, Soo AP, Eguchi S, Gu J, Ma DA-O: The role of osteopontin in the progression of solid organ tumour. (2041-4889 (Electronic)).

21. Kothari AN, Arffa ML, Chang V, Blackwell RH, Syn W-K, Zhang J, Mi Z, Kuo PC: Osteopontin-A Master Regulator of Epithelial-Mesenchymal Transition. Journal of Clinical Medicine2016, 5(4).

22. Prochazka L, Tesarik R, Turanek J: Regulation of alternative splicing of CD44 in cancer. Cellular Signalling2014, 26(10):2234-2239.

23. Hu J, Li G, Zhang P, Zhuang X, Hu G: A CD44v+ subpopulation of breast cancer stem-like cells with enhanced lung metastasis capacity. Cell Death \& Disease2017, 8(3):e2679-e2679.

24. Zlobec I, Lugli A: Epithelial mesenchymal transition and tumor budding in aggressive colorectal cancer: tumor budding as oncotarget. Oncotarget2010, 1(7):651-661.

25. Todaro M, Gaggianesi M, Catalano V, Benfante A, lovino F, Biffoni M, Apuzzo T, Sperduti I, Volpe S, Cocorullo Get al: CD44v6 Is a Marker of Constitutive and Reprogrammed Cancer Stem Cells Driving Colon Cancer Metastasis. Cell Stem Cel/2014, 14(3):342-356.

26. Fodde R: The APC gene in colorectal cancer. European Journal of Cancer2002, 38(7):867-871.

27. Wielenga VJM, Smits R, Korinek V, Smit L, Kielman M, Fodde R, Clevers H, Pals ST: Expression of CD44 in Apc and TcfMutant Mice Implies Regulation by the WNT Pathway. Am J Patho/1999, 154(2):515-523.

28. Rangaswami H, Bulbule A, Kundu GC: Osteopontin: role in cell signaling and cancer progression. Trends in Cell Biology2006, 16(2):79-87.

29. Coppola D, Hyacinthe M, Fu L, Cantor AB, Karl R, Marcet J, Cooper DL, Nicosia SV, Cooper HS: CD44V6 expression in human colorectal carcinoma. Human Pathology1998, 29(6):627-635.

30. Bellahcène A, Castronovo V, Ogbureke KUE, Fisher LW, Fedarko NS: Small integrin-binding ligand Nlinked glycoproteins (SIBLINGs): multifunctional proteins in cancer. Nature Reviews Cancer2008, 8(3):212-226.

31. Yu X, Zheng Y, Zhu X, Gao X, Wang C, Sheng Y, Cheng W, Qin L, Ren N, Jia Het al: Osteopontin promotes hepatocellular carcinoma progression via the PI3K/AKT/Twist signaling pathway. Oncol Lett2018, 16(4):5299-5308.

32. Yilmaz M, Christofori G: EMT, the cytoskeleton, and cancer cell invasion. Cancer and Metastasis Reviews2009, 28(1):15-33.

33. Ma L, Dong L, Chang P: CD44v6 engages in colorectal cancer progression. Cell Death \& Disease2019, 10(1):30.

34. Jolly MK, Boareto M, Huang B, Jia D, Lu M, Ben-Jacob E, Onuchic JN, Levine H: Implications of the Hybrid Epithelial/Mesenchymal Phenotype in Metastasis. Frontiers in Oncology2015, 5:155.

35. Jolly MK, Tripathi SC, Jia D, Mooney SM, Celiktas M, Hanash SM, Mani SA, Pienta KJ, Ben-Jacob E, Levine H: Stability of the hybrid epithelial/mesenchymal phenotype. Oncotarget2016, 7(19):2706727084. 
36. Gloushankova NA, Zhitnyak IY, Rubtsova SN: Role of Epithelial-Mesenchymal Transition in Tumor Progression. Biochemistry (Moscow)2018, 83(12):1469-1476.

37. Cheng Y, Wen G, Sun Y, Shen Y, Zeng Y, Du M, Zhu G, Wang G, Meng X: Osteopontin Promotes Colorectal Cancer Cell Invasion and the Stem Cell-Like Properties through the PI3K-AKT-GSK/3ß及/Catenin Pathway. Med Sci Monit2019, 25:3014-3025.

38. Sato K, Uehara T, Iwaya M, Nakajima T, Miyagawa Y, Ota H, Tanaka E: Correlation of clinicopathological features and LGR5 expression in colon adenocarcinoma. Annals of Diagnostic Pathology2020, 48:151587.

39. Ng L, Wan T, Chow A, lyer D, Man J, Chen G, Yau TC-C, Lo O, Foo C-C, Poon JT-Cet al: Osteopontin Overexpression Induced Tumor Progression and Chemoresistance to Oxaliplatin through Induction of Stem-Like Properties in Human Colorectal Cancer. Stem Cells Internationa/2015, 2015:247892.

\section{Figures}

Fig. 1
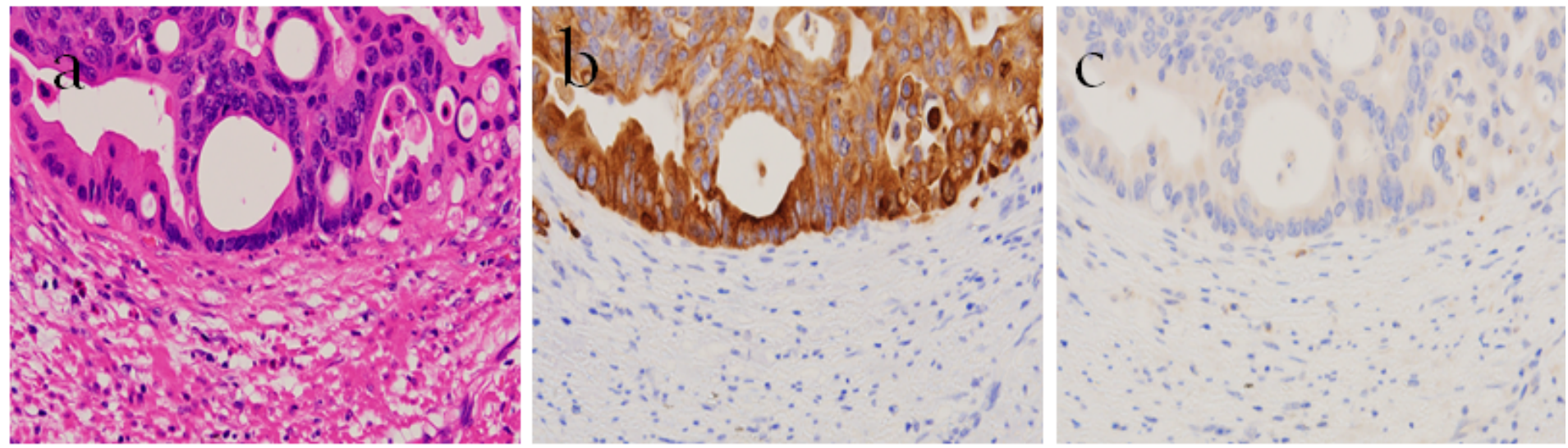

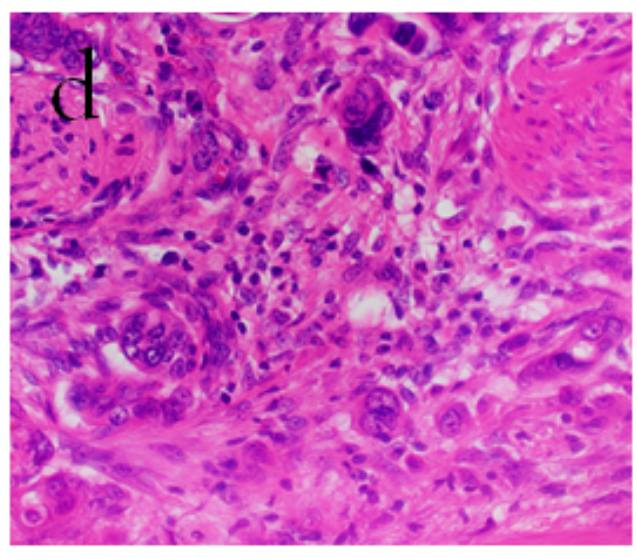

$\mathrm{HE}$

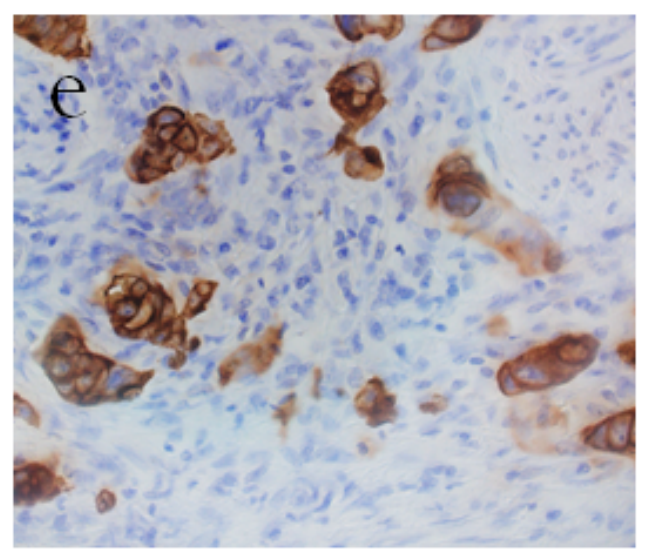

Cytokeratin $\mathrm{AE} 1 / \mathrm{AE} 3$

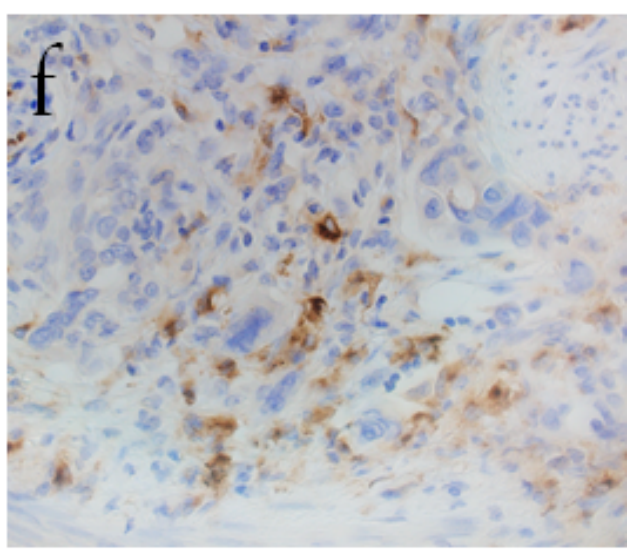

OPN

Figure 1 
Representative images of OPN.

Representative features of low OPN expression (a and c) and high OPN expression ( $d$ and $f$ ). Immunohistochemistry of cytokeratin AE1/AE3 in OPN-low (b) and OPN-high (e) tissue. (a and d, HE; b and e, cytokeratin AE1/AE3 immunostaining; $c$ and $f, O P N$ immunostaining.)

\section{Fig. 2}

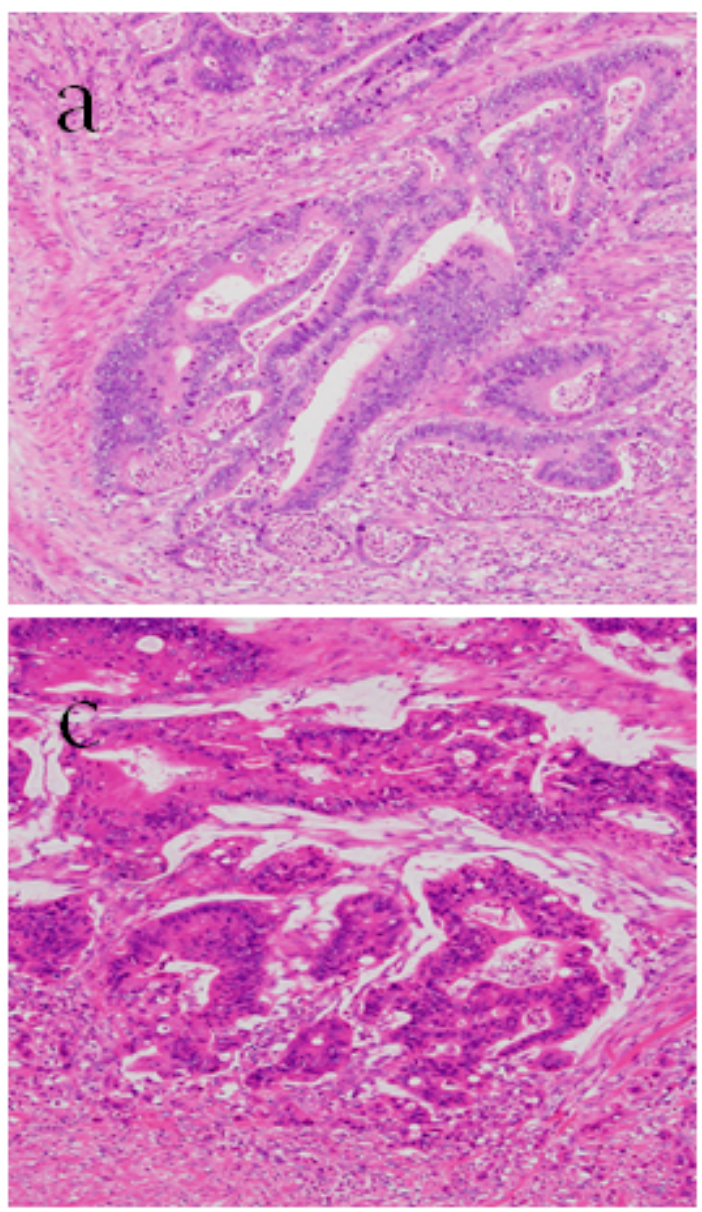

$\mathrm{HE}$
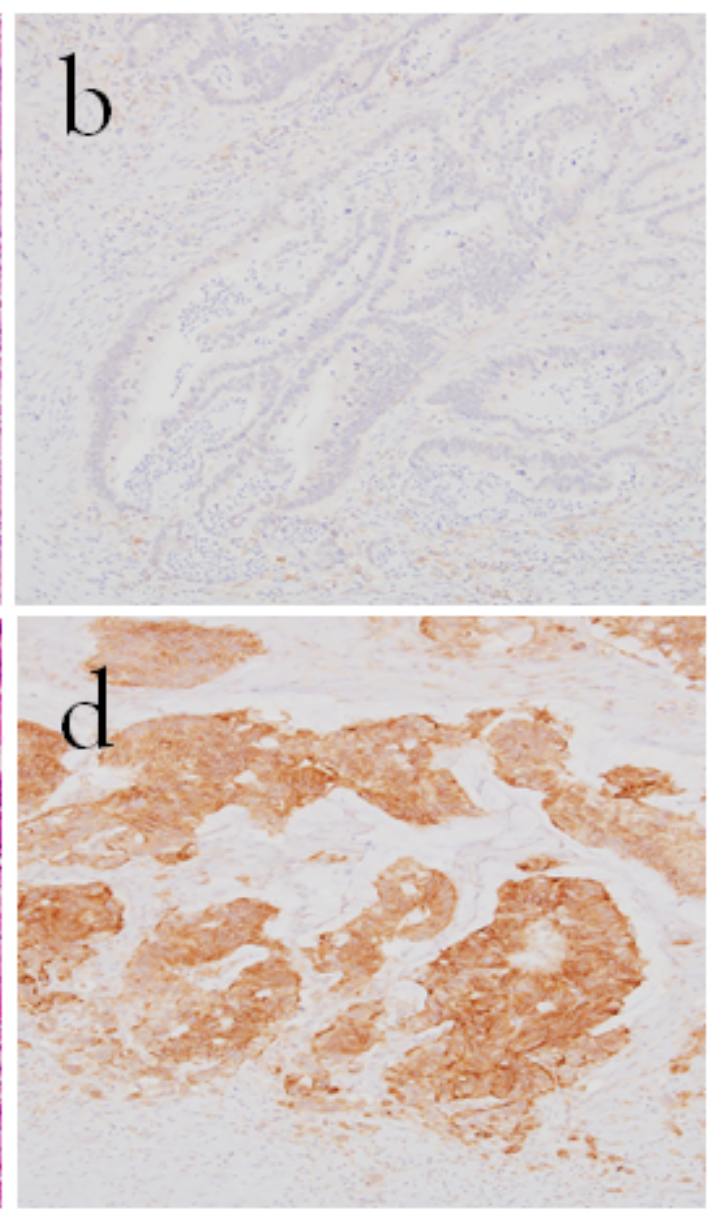

CD44v6

\section{Figure 2}

\section{Representative images of CD44v6.}

Representative features of negative expression of CD44v6 ( $a$ and $b$ ) and positive expression of CD44v6 (c and d). (a and c, HE; b and d, CD44v6 immunostaining.) 
Fig. 3

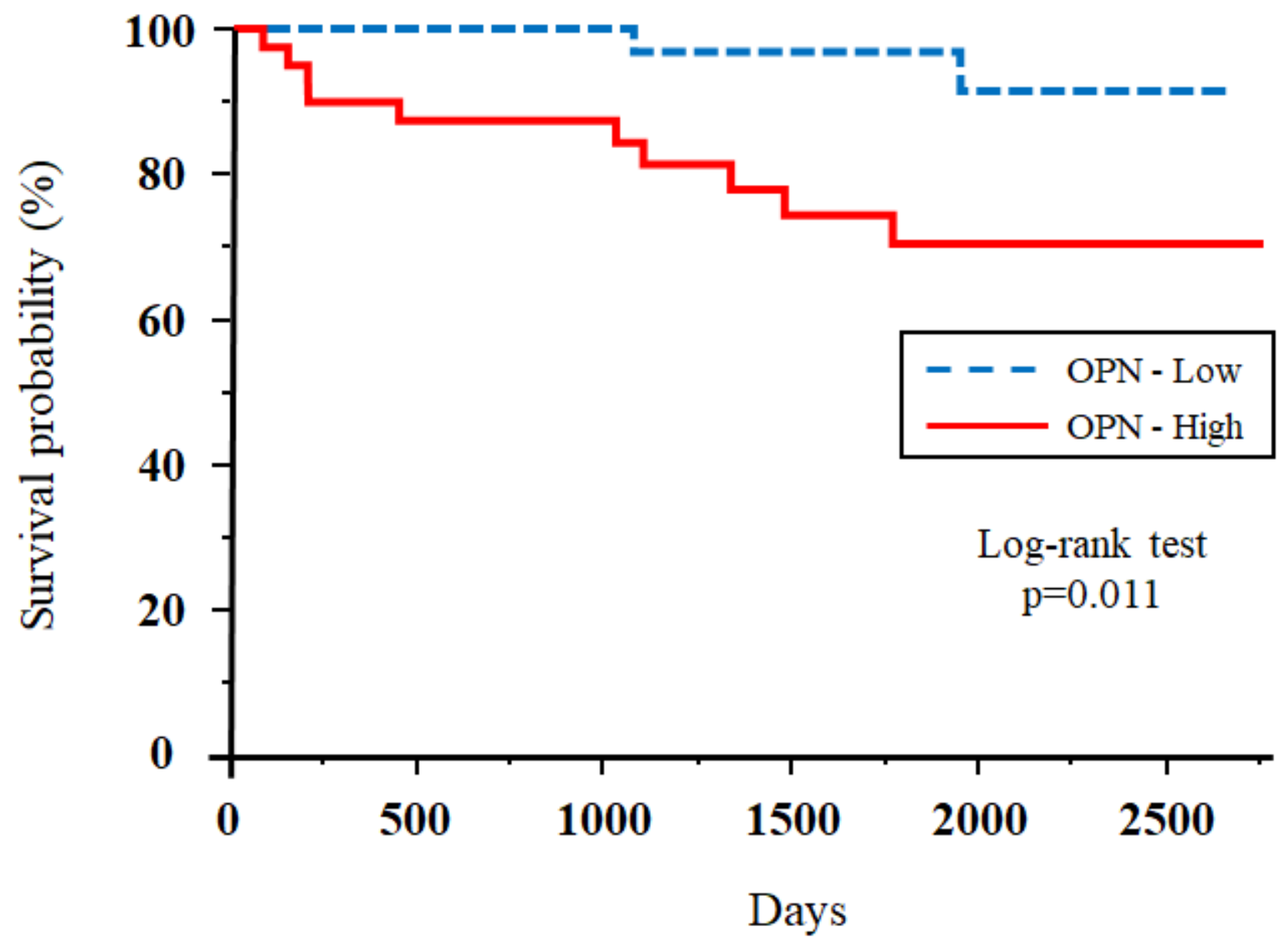

Figure 3

Kaplan-Meier survival curves of patients classified according to OPN expression.

A statistically significant effect was found in overall survival (OS) between the OPN-positive group [median OS: 1586 (range, 30-2749) days] and the OPN-negative group [median OS: 1901 (range, 82665) days] (log-rank test, $\mathrm{p}=0.011$ ) 